\title{
VEGFR OVEREXPRESSION AS A PROMISING PREDICTIVE AND PROGNOSTIC BIOMARKER FOR BREAST CANCER
}

\author{
Kamal B Siregar \\ ${ }^{1}$ Department of Surgery, University of Sumatera Utara at H. Adam Malik Hospital, Medan.
}

\begin{abstract}
Background:

The majority of breast cancer cases are presented in an advanced stage; hence, there is a need to have a biomarker that is able to function both as a predictive and prognostic tool for breast cancer. Since angiogenesis has been found to be closely related to the invasiveness of breast cancer, angiogenic marker such as vascular endothelial growth factor (VEGF) may be a promising marker for this cancer.
\end{abstract}

\section{Objective:}

The aim of this study is to determine the association between the VEGF receptor (VEGFR) expression with human epidermal growth factor receptor-2 (HER-2)/ neu and estrogen receptor (ER)/progesterone receptor (PR) expression in an attempt to clarify the role of VEGFR as a potentially novel predictive and prognostic biomarker for breast cancer.

\section{Materials and Methods:}

This study examined 40 tissue biopsies taken from patients diagnosed with breast cancer in $\mathrm{H}$. Adam Malik Hospital Medan, Indonesia. Samples were analyzed by immunohistochemistry to determine the histopathology, grading, lymphovascular invasion and expression of VEGFR, HER-2/neu and ER/PR. Association between dependent and independent variables was conducted using chi-square test and logistic regression.

\section{Results:}

The majority of the cases in this study were infiltrating ductal carcinoma (90\%), in stage III (70\%), and showed positive TIL (75\%). VEGFR expression was found to be upregulated in 21 samples (52.5\%). HER-2/neu was positive in 14 patients (35.0\%) and ER/PR was positive in 22 patients (55\%). The expression of VEGFR positively correlated with HER-2/neu expression $(p=0.002)$ and negatively correlated with ER/PR expression $(p=0.012)$.

\section{Conclusion:}

Overexpression of VEGFR is a potential valuable predictive and prognostic biomarker for breast cancer. Antagonising VEGFR may serve as the future target therapy for the disease.

\section{Background}

Breast cancer remains a major problem in many countries. The reported worldwide incidence of breast cancer in women is 126 for every 100,000 cases, whilst its incidence in the male population is 0.6 for every 100,000 cases (1). In the United States, breast cancer is the most common malignancy with 180,000 new cases reported annually (2). In developing countries such as Indonesia, there are approximately 20,000 new cases of breast cancer each year, of which more than $50 \%$ of these cases are found to be in an advanced stage (3).

The invasiveness and rate of metastasis of breast cancer cells have been found to be closely related to angiogenesis (4). This is a mechanism that helps to maintain the metabolism, growth, and nutritional supply of tumor cells (5). Vascular endothelial growth factor (VEGF) is an angiogenic factor that plays an important role in maintaining the growth of tumors $(6,7)$. Various studies have shown that mRNA and serum VEGF levels increase along with the rate of metastasis because VEGF aid in the formation of new vessels, which bring nutrients and oxygen for cancer cells to grow and spread. Hence, VEGF may potentially be a suitable biomarker to predict the prognosis and response to chemotherapy in patients with breast cancer $(8,9)$. The level of VEGF is better represented by the quantity of its receptor because aggregated platelet, activated neutrophil, and lymphocytes can ameliorate its serum level (10). VEGFR-I/FIt-1 is a tyrosine kinase receptor, which binds to VEGF-A, VEGF-B, and PIGF, and plays a role in collagen breakdown and hematopoiesis. On the other hand, VEGFR-2/KDR is a domain kinase receptor that binds 
to VEGF with high affinity and plays a role in angiogenesis and hematopoiesis $(6,11)$.

Breast cancer can be classified into luminal type $A$, luminal type B, HER-2 type, and basal type, based on different gene expressions. In developing countries, many of the more technologically advanced tests cannot be performed because of financial constraints and relatively poor health care facilities. Therefore, there is a need to use a biomarker that can function as a general screening tool for all types of breast cancer. Various studies have confirmed the role of HER-2/neu and ER/PR as a very valuable rapid proliferation marker of cancer cells, which function both as a predictive and prognostic factor in breast cancer. However, the relationship between HER-2/neu and ER/PR expression with vascular endothelial growth factor (VEGF) has not been fully defined. Thus, the aim of the study is to determine the level of VEGFR and its association with HER$2 /$ neu and ER/PR expression in a localised population of patients with breast cancer. Any association found between those markers will support the use of VEGFR as a novel predictive and prognostic biomarker for breast cancer.

\section{Materials and Methods}

\section{Samples}

Biopsies were collected from 40 patients diagnosed with breast cancer who were scheduled for elective surgery in H. Adam Malik Hospital, Medan, from October 2013 to December 2013. Patients who had received both radiotherapy and chemotherapy, and who suffered from other cancers, and metabolic syndromes, were excluded from the study. This study was approved by the Ethics Committee of the Faculty of Medicine, University of Sumatera Utara. Written informed consent was obtained from each participant prior to the commencement of the study.

Medical record, biopsy collection, and processing of paraffin blocks were collected by different observers blinded to the study. Specimens were processed in the Department of Pathology, University of Sumatera Utara, by hematoxylin eosin staining to examine the histopathology, grading, vascular invasion and lymphatic invasion. Samples were further sent to the Department of Pathology, Gadjah Mada University, Yogyakarta, to determine the expressions of VEGFR, HER-2/neu and ER/PR.

\section{Study criteria}

The expressions of vascular endothelial growth factor receptor (VEGFR), HER-2/neu, estrogen (ER) and progesterone $(P R)$ receptors in the primary tumor were also determined by immunohistochemistry. VEGFR was regarded as being overexpressed if the positively stained cells were $>42.5 \%$ of the total cell population, and unexpressed if the stained cells were $<42.5 \%$. HER- $2 /$ neu was regarded as positive if the positively stained cells were $>10 \%$, and negative if the stained cells were $<10 \%$. ER was considered positive if the stained cells were $>10 \%$, and negative if the stained cells $<10 \%$. PR was regarded as positive if the positively stained cells were $>10 \%$, and negative if the stained cells $<10 \%$.

\section{VEGFR analysis}

Paraffin blocks were sliced by $\pm 1-2$ microns thick, placed in special glass object, deparafinnated, then washed with Phosphate Buffer Saline (PBS), 3-5 times for 5 minutes. Antigen retrieval was carried out using citrate buffer $\mathrm{pH}$ 60 and heated to $95^{\circ} \mathrm{C}$, two times for 5 minutes, then allowed to cool, and washed again with PBS, 3-5 times, each lasting for 5 minutes. Specimens were then treated with normal rabbit serum for 10 minutes, followed by monoclonal VEGFR with 1: 100 dilution (Kione TLC-9 Novocastra) overnight at room temperature. Samples were then washed again with PBS, 3-5 times, 5 minutes each time. Secondary antibody was added for 30 minutes. Samples were rewashed again with PBS, 3 times, followed by addition of streptavidin bioin complex (SABC from Daco) for 30 minutes, and washed again with PBS, 3 times for 5 minutes. Diamine benzidine was added for 3 minutes, and then washed with sterile water. The specimens were stained with Mayer's hematoxylin solution for 20 seconds to 1 minute and washed with running water. Specimens were then examined under the microscope, at a magnification of $100 \times 400$. Stained cells were calculated by 10 times sliding and the averaged results were collected.

\section{Statistical analysis}

Statistical analysis was done by SPSS 17.0, Inc (Chicago, IL). Association between dependent and independent variables was conducted using chi-square test and logistic regression. Significance level is set at $p \leq 0.05$

\section{Results}

\section{Patients and tumor biopsies}

The characteristics of patients in this study are shown in Table 1. The primary locations of the breast cancer were in the right breast (77.5\%) and in both lateral upper quadrant and central quadrant (30.0\%), respectively. Infiltrating ductal carcinoma accounts for $90 \%$ of the breast cancer cases. The majority of the patients were in stage III (70\%); 30 patients $(75.0 \%)$ obtained a positive TIL, and 30 patients (75.0\%) show no lymphovascular invasion.

\section{VEGFR, HER-2/neu, and ER/PR expression}

On immunohistochemistry examination, VEGFR expression was found to be overexpressed in 21 samples (52.5\%) and unexpressed in 19 samples (47.5\%). HER-2/neu was found to be positive in 14 patients (35.0\%) and ER/PR was positive in 22 patients (55\%). VEGFR was overexpressed in $12 / 24$ HER-2/neu positive compared to only $9 / 26$ in HER-2/neu negative samples. Chi square analysis revealed a significant association between overexpression of VEGFR and positivity of HER-2/neu expression ( $X^{2}$ 9.52, 
Table 1: Characteristics of breast cancer patients in this study

\begin{tabular}{|c|c|c|}
\hline Characteristics & Total number of patients & Percentage of patients (\%) \\
\hline \multicolumn{3}{|l|}{ Age } \\
\hline$<25$ & 1 & $2,5 \%$ \\
\hline $26-40$ & 12 & $30 \%$ \\
\hline $41-65$ & 26 & $65 \%$ \\
\hline$>65$ & 1 & $2,5 \%$ \\
\hline \multicolumn{3}{|l|}{ Stage } \\
\hline 1 & 2 & $5 \%$ \\
\hline II & 2 & $5 \%$ \\
\hline III & 28 & $70 \%$ \\
\hline IV & 8 & $20 \%$ \\
\hline \multicolumn{3}{|l|}{ Histopathology } \\
\hline LDC & 36 & $90 \%$ \\
\hline Lobular Ca & 2 & $5 \%$ \\
\hline Tuular. Ca & 1 & $2,5 \%$ \\
\hline Mucinous Ca & 1 & $2,5 \%$ \\
\hline \multicolumn{3}{|l|}{ Grading } \\
\hline Grade I & 6 & $15 \%$ \\
\hline Grade II & 18 & $45 \%$ \\
\hline Grade III & 16 & $40 \%$ \\
\hline \multicolumn{3}{|l|}{ Tumor location } \\
\hline Upper lateral & 12 & $30 \%$ \\
\hline Lower lateral & 7 & $17,5 \%$ \\
\hline Upper median & 5 & $12,5 \%$ \\
\hline Lower median & 4 & $10 \%$ \\
\hline Cental & 12 & $30 \%$ \\
\hline \multicolumn{3}{|l|}{ TIL } \\
\hline Positive & 30 & $75 \%$ \\
\hline Negative & 10 & $25 \%$ \\
\hline \multicolumn{3}{|c|}{ Lymphovascular invasion } \\
\hline Positive & 10 & $25 \%$ \\
\hline Negative & 30 & $75 \%$ \\
\hline \multicolumn{3}{|l|}{ HER-2/neu } \\
\hline Positive & 14 & $35 \%$ \\
\hline Negative & 26 & $65 \%$ \\
\hline \multicolumn{3}{|l|}{ P53 } \\
\hline Positive & 13 & $32,5 \%$ \\
\hline Negative & 27 & $67,5 \%$ \\
\hline \multicolumn{3}{|l|}{$E R / P R$} \\
\hline Positive & 22 & $55 \%$ \\
\hline Negative & 18 & $45 \%$ \\
\hline \multicolumn{3}{|l|}{ VEGFR } \\
\hline Overexpressed & 21 & $52,5 \%$ \\
\hline Unexpressed & 19 & $47,5 \%$ \\
\hline
\end{tabular}

$p=0.002 ;$ OR: $11.33 ; 95 \% \mathrm{Cl}: 2.06-62.1)$. On the other hand, VEGFR was overexpressed in 16/18 ER/PR negative, compared to only 5/22 in HER-2/neu positive samples. A significant association between overexpression of VEGFR and negativity of ER/PR expression was also demonstrated $\left(X^{2}\right.$ 6.32, $p=0.002$; OR: 0.182; 95\% Cl: $\left.0.04-0.71\right)$.

\section{Discussion}

Breast cancer is a solid cancer that is difficult to treat due to its rapid behavior of metastasis. In line with the tremendous development of biomolecular research, diagnosis and therapy of breast cancer are now improved. Since metastasis is largely influenced by angiogenesis, VEGFR may have an important role as a predictive biomarker for breast cancer. Malignant transformation of cells in culture condition is associated with an increased expression of VEGFR to support their growth (12).

VEGF binds to tyrosine kinase receptors i.e. VEGFR-1 (Flt1), VEGFR-2 (FIk-I/KDR) and VEGFR-3 (Flt-4). Receptors are then deformed, dimerized, and autophosphorylated. This will induce signal transduction, resulting in endothelial cell proliferation, activation of mitogen-activated protein kinase (MAPK), protein kinase C (PKC) and Akt pathway. This will lead to migration of endothelial cells, involving the induction of MMP activation of focal adhesion kinase and phosphatidylinositol 3'-kinase (PI3-K). Nitric oxide serves as a mediator for vasodilation, proliferation, and migration of endothelial cells in response to VEGF. 
Table 2: Association of VEGFR and HER-2/neu expression

\begin{tabular}{lcccc}
\hline & \multicolumn{2}{c}{ Her2/Neu } & Total & $p$ \\
& Positive & Negative & & \\
\hline Overexpressed & 12 & 9 & 21 & 0.002 \\
Unexpressed & 2 & 17 & 19 & \\
Total & 14 & 26 & 40 & \\
\hline
\end{tabular}

Table 3: Association of VEGFR and ER/PR expression

\begin{tabular}{lcccc}
\hline & \multicolumn{2}{c}{ EKSP.ER/PR } & Total & $p$ \\
& Positive & Negative & & 0.002 \\
Overexpressed & 5 & 16 & 21 & 19 \\
Unexpressed & 17 & 2 & 40 & \\
Total & 22 & 18 & & \\
\hline
\end{tabular}

Angiogenesis-induced VEGF does not only promote the growth of endothelial cells but also inhibit apoptosis through activation of Akt-PI3-K pathway. VEGF also regulates expression of several anti-apoptotic proteins, such as $\mathrm{Bcl}-2$. This protein ultimately inhibits caspase activation and regulates the expression of $\mathrm{X}$-chromosomelinked inhibitor of apoptosis family of proteins. This mechanism is caused by the destruction of immature blood vessels as an effect of low VEGFR expression (13).

VEGFR has been previously tested as a biomarker that can function generally for all types of breast cancer (12). HER2/neu and ER/PR have been confirmed as the promising marker in breast cancer. If there were associations between HER-2/neu and ER/PR with VEGFR, then VEGFR can be a valuable biomarker in general types of breast cancer. Changes in estrogen and progesterone levels induce remodelling of breast cancer epithelial, stroma, and vascular tissues (13). A previous study involving the San Antonio patient database showed that negativity of ER/ PR in terminal ductal breast cancer cells induced cancer cells differentiation and lymphovascular invasion (14). McPherson et al. found that ER negative-breast cancer was linked to rapid tumor cell growth and angiogenesis, which was shown by increased thymidin labeling index, mitotic index, and microvessel density (15). In this study, there was a significant association between the overexpression of VEGFR with negativity of ER/PR. Linderhaim et al. also found an association between these parameters in progressive proliferated and invasive, mainly on invasive ductal breast carcinoma.

In a previous study, Bilious et al. showed that gene amplification and overexpression of HER-2/neu was a poor prognostic factor for breast cancer (16), as well as for disease recurrence and patients' survival rates
(17). High cell proliferation and grading with HER-2/neu overexpression requires angiogenesis to maintain sufficient nutrition and metabolism for tumor cell development (18). In this study, a significant association between the overexpression of VEGFR with positivity of HER-2/neu was found. A study by the American Association for Cancer Research also showed that high VEGF levels correlated with high HER-2/neu (19).

VEGFR overexpression was also found to be closely associated with tumor invasion into the lymphatic vessels. Lymphovascular invasion is correlated with tumor size, histopathology grading, and lymph node metastasis (20). Clinical trials in cancer patients with VEGFR inhibitors, including anti-VEGFR monoclonal humanized antibody (mAb VEGFrhu) showed promising results. Phase III of randomized controlled trial study in metastatic colorectal cancer demonstrated significant increase in overall rate of survival with VEGF mAb rhu therapy (21).

This study was conducted in one of the tertiary referral centers in Indonesia; hence, it has an advantage of representing a larger population of breast cancer cases in Indonesia. However, the limitation of this study was that the majority of breast cancer types was invasive ductal carcinoma, in which the usual tumor sizes were larger and histological grading and mitotic indices were higher, so that logically, the levels of VEGFR tend to be higher.

\section{Conclusion}

Overexpression of VEGFR showed significant association with positivity of HER-2/neu expression and negativity of ER/PR expression. Thus, VEGFR might serve as a suitable new biomarker for breast cancer. Further research with larger sample size is needed to improve the reproducibility of the study. 


\section{Abbreviations}

ER/PR: Estrogen receptor/Progesteron receptor, HER2/neu: Human Epidermal growth factor Receptor 2/ neu, MAPK: Mitogen-activated protein kinase, PI3K: Phosphatidylinositol 3'-kinase, PBS: Phosphate Buffer Saline, PKC: Protein kinase C, TIL: Tumor infiltrating lymphocyte, VEGF: Vascular endothelial growth factor, VEGFR: Vascular endothelial growth factor receptor

\section{Competing interests}

The author declares that he has no competing interests.

\section{References}

1. Baas PC, van Beek TLSA, van Bekkum D, Beijert $M$, Blok FHJ, Bong $S B$, van den Broek RWFR, Doisma WV, 2003. Mammacacinoom, In Otter $\mathrm{R}$ en de tumorwekgroepen (eds): Richthjmen voor diagnostiek en behandeling van premaligna en maligne aandoeningen inj de JKN-regio, IKN, Groningen : 315-363

2. Osborne CK, Bardou V, Hopp TA, et al. Role of the estrogen receptor coactivator AIB1 (SRC-3) and HER2/neu in tamoxifen resistance in breast cancer. J. Natl. Cancer Inst. 2003; 95(5):353-361.

3. Tjindarbumi D. Pengelolaan multidisiplin untuk mencapai kulaitas hidup yang lebih baik pada penderita kanker payudara, Muktamar nasional VI Peraboi, Semarang, 2003.

4. Steeg PS, Harris Jay R, Lippman, Marc E, Morrow $M$. Control of invasion and metastasis. Diseases of the breast $3^{\text {rd }}$ ed. Philadelphia: Lippincott Williams \& Wilkins; 2005.

5. Brown MR, Masiero L, Kohn EC,. Tumor Angiogenesis and Metastasis. In: Hoskins WJ, Perez CA, Young RC. Principles and practice of Gynocologic Oncology. $3^{\text {rd }}$ ed. Lippincott Williams and Wilkins; 2000. p. 87-101.

6. Ferrara N. Vascular endothelial growth factor and the regulation of angiogenesis. Rec Prog Horm Res. 2000;55:15-36.

7. Tou M, Mastsumoto T, Bando H, 2001. Vascular endothelial growth factor: its prognostic, predictive, and therapeutic implications. Lancet Oncol. 2:667-673.

8. Lissoni P, Fugamalli E, Maligani F, 2000. Chemotherapy and angiogenesis in advanced cancer: Vascular endothelial growth factor (VEGFR) decline as predictor of disease control during taxol therapy in metastatic breast cancer. Int J Biol Markers 15:308-311.

9. Byne GJ, Bundred NJ. Surrogate markers of tumoral angiogenesis. Int J Blot Markers 2000;15:334-339.
10. Adams J, Carder PJ, Downey S. Vascular endothelial growth factor (VEGFR) in breast cancer: Comparison of plasma, serum, and tissue VEGFR and microvessel density and effects of tamoxifen. Cancer Res 2000;60:2898-2905.

11. Hoar FJ, Chaudhri S, Wedley MS. Coexpression of vascular growth factor C (VEGFR-C) and c-erbB-2 in human breast carcinoma. Eur J Cancer. 2003;39: 1698-1703.

12. Leong A S-Y, Lee AKC. Biological Indices in the assessment of breast cancer. J Clin. Pathol. 1995;48:221-38.

13. Coradini D, Biganzli E, Pellizaro C. Vascular endothelial growth factor in node-positive breast cancer patients treated with adjuvant tamoxifen. $\mathrm{Br} J$ Cancer. 2003;89:268-270.

14. Wittliff JL. Hormone And Growth Factor Receptors. In: Donegan WL, Spratt JS (eds): Cancer of the breast. WB Saunders Company, Philadelphia; 1998. p. 346-374.

15. McPherson K, Steel CM, Dixon JM. ABC of Breast Diseases. Breast cancer-epidemiology, risk factors, and genetics. BMJ 2000;321;624-628

16. Bilous M, Ades C, Armes J, Bishop J, Brown R, Cooke $B$, et al. Predicting the HER-2 status of breast cancer from basic histopatology data: and analysis of 1500 breast cancer as part of the HER-2 International Study. The Breast 2003;12:92-98

17. Clark GM, 2000. Prognostic and Predictive Factors. Dalam: Harris JR, Lippman ME, Morrow M. Osborne $\mathrm{Ck}$ (eds). Disease of the Breast. Second edition, Lippincot, Williams \& Wilkinds, Philadelphia; 2000 p. 489-514.

18. Callagy G, Dimitriadis E, Harmey J. Immunohistochemical measurement of tumor vascular endothelial growth factor in breast cancer. A more reliable predictor of tumor stage than microvessel density of serum vascular endothelial growth factor. Appl Immunokistochem Molecul Morphol. 2000;8:104-109.

19. Konecny GE, Meng YG, Untch M. Association between HER-2/neu and vascular endothelial growth factor expression predicts clinical outcome in primary breast cancer patients. Clinical Cancer Res. 2004;10: 1706-1716.

20. Langlands AO, Gebski V, Hisrch D, Tattersall MHN. Delay in the clinical diagnosis of breast cancer: estimating its effect on prognosis, with particular reference to medical litigation. The Breast 2002;11: 386-39. 